\title{
Role of Youth Diplomacy in Governments' Foreign Relationships by Using YNGOs Capacity (Youth Non-governmental Organizations)
}

\author{
Rohollah Modaber ${ }^{1}$ \\ ${ }^{1}$ Department of Political Science \& International Relation, College of Law and Political Science, Tehran Science \\ and Research Branch, Islamic Azad University, Tehran, Iran \\ Correspondence: Rohollah Modaber, Department of Political Science \& International Relation, College of Law \\ and Political Science, Tehran Science and Research Branch, Islamic Azad University, Tehran, Iran. E-mail: \\ Modaber21@yahoo.com
}

Received: March 5, 2016 Accepted: March 27, 2016 Online Published: March 31, 2016

doi:10.5539/jpl.v9n2p219 URL: http://dx.doi.org/10.5539/jpl.v9n2p219

\begin{abstract}
In current world, regarding the daily event occur in human communications domain, the process of international problems causes blurring the role of governments and this new situation leads to evolution in common traditional diplomacy of past centuries. Parallel with the communities' evolution, it is evident, new scenarios engender in diplomacy and international relations arena which seek the modern preferences along methods adoption and modern means like using non-governmental players capacity especially NGOs. Regarding the youth role-playing in various countries specially developed onesas a thinking, work and providing ideas forces in institutions, scientific and administrative centers and the YNGOsdevelopment process in the global system along various programs including welfare and philanthropic measures beyond the countries' boundary; and creating active youth global network and developing this network in most youth communities along influence in philanthropic and universal programs in international arena which causes the influence on the minds of different masses of people and even governments and international organizations; new discourse with the title of youth diplomacy as modern diplomacy is created. Therefore, the present study aimed toinvestigate what is the role of youth diplomacy in developing philanthropic discourse and promoting welfare measures in international system by using NGOs. It seems, meanwhile, moving in the way of developing mutual understanding among youth in other countries, who has motivation and concerns to encounter the spread of war, ethnic conflicts, migration, the spread of AIDS, environmental degradation and other similar cases; will be the reason of the creation of the effective youth global network in countries along governments and YNGOs-orientated by unofficial meanshave the approach of achieving a better future in order to achieve the peace and pressure on the governments have the role in promoting violence and extremism.
\end{abstract}

Keywords: modern diplomacy, youth diplomacy, youth non-governmental organizations (YNGOs), global confidence

\section{Introduction}

Although it seems Marshall McLuhan's global village was not completely replaced nation-state, by ending the Cold War, today's communication environment among communities, it seems, has connected people to each other, so that, this situation was unpredictable for the governments' leaders. Due to the official traditional diplomatic relations lag, this led to entrance of modern diplomatic era and the analysis of the transnational relations versus the traditional concepts of international relations. Putting in other words, from the dominant paradigm of international relations perspective which emerged, based on Westphalia treaty for nation-states, after defining the global system, the results and actions of the nations' relationships with each other cannot be included in it.

It is obvious that new scenarios were emerged parallel to the created evolutions in communications era, in the international relations which look modern preferences along with the adoption of modern methods. Adhering to the principles, objectives, and classical diplomatic figures do not meet the modern diplomatic needs anymore. The new balance is the production of an environment full of events and modern opportunities of the development and growth of the modern technology in communication and information; The complexity of the growth and the spread of the utilization of the communication and information's modern technologies; The complexity of 
interdependence, culture globalization, public opinion empire, the growth of virtual environment and Internet technology, the cultural movement flow in international system, opinions, information and the relation of this puzzle with youth as the most important technology users. The virtual environment puts pressure on national governments as the modern factor and forces them to reconsider the structures of foreign policy model, the process of their traditional diplomacy and transform it.

Due to the priority of the official and channels role of government, the above evolutions move in this direction due to the lack of accountability of traditional diplomacy to relation and recruitment among nations. The atmosphere of the modern policy illustrates the necessity of promoting the public diplomatic means aimed at influencing on the public thoughts and elites of other nations to gain privilege and make necessary to move in the way of the national interests, is one of the states' arms in youth foreign and domestic policy arena. The youthsare the most users of the virtual environments, cultural products, means of pleasure and leisure, attendees in ceremonies and national programs and the provocative engine work in community in all spheres especially the cultural ones. The active and interestedyouths to countries can act as the most important increasing soft power factors of countries after training in the cultural, scientific, media, cinema fields and organizing in YNGOs, in order to help the national interests, affect the public thoughts of other nations, create the depth of influence in foreign audiences, send to other countries, promote programs and the strengths of the country, respect to the reflected reports and the images by domestic media, exchange the philanthropic thoughts and form a network of youth elites interested in public well, etc. Transferring the values and mutual effect of countries are forming by the span and unbelievable acceleration due to the rising in universal modern communication and the daily proximity of nations.

Meanwhile, youth diplomacy is affective on international politics programs by non-governmental diplomatic players. They entered in various arenas to ascertain their goals. It is noteworthy the success of non-governmental organizations in their goals realization is due to the proper and effective usage of the new information technology and entrance to the global network.

\section{Theoretical Framework}

In this present study, according to the position of international organizations and NGOs to neoliberalism philosophers as the peace promoting capacity and philanthropic actions, in the universal approach this theory is used to promote nongovernmental organizations along with liberalideas. It is worth noting that, in the world, the most important factors in developing the NGOs are as the main carrier of social capital, providing the growth and recruiting conditions and forming these organizations in civil society. Social capital is not in the physical form but it is the result of the interactions and group and social norms and its increasing leads the serious reduction in the level of the managing costs of society and the operational cost of organizations and has the direct relation with the national interests and security that it would achieve in civil society.

The neoliberalism discourse is the result of the years after the Second World War and the pundits need to reconsider in this paradigm, and after the League of Nations defeat in preventing the Second World War occurrence. Neoliberalism is an effort for explaining the progress in universal politic economy after the Second World War, by emphasizing and focusing on the key role of institutions and organizations in international policy.

Robert K. (1982) and Stephen K. (1983)'s works were the most effective works in this traditional method. The main idea of these two thinkers was based on the observation of the cooperative models and the relative stability of these patterns in international political economy. They believe that regarding the heterogeneity of the economy power in the international level, we are seeing more stability in the universal community level, in the event of the nations' economic cooperation. 1970s economic and political events in the universal community level have contributed greatly in progress of this discourse.

Serious development of classical liberalism discourse by these philosophers, and promoting it to a new discourse are the result of adding new concepts to this field in which the most important concept is the term "international regimes". The idea of looking to the international regimes requires this assumption that the concept of cooperation replaces other concepts in international institutions, such as UN. Indeed, these institutions were not international organizations with superficial rules and ongoing processes governing them, but yet international economic agreements were acted which help to form and regulate the governments' behavior.

Although for centuries, the dream of founding international organizations and NGOs were occupied minds of human to provide global peace, however, the expressed theories were far from reality. In the $17^{\text {th }}$ and $18^{\text {th }}$ centuries, some works were published in which apparently were referred to founding international organizations. Jeremy Bentham, Jean-Jacques Rousseau, Abbé de Saint-Pierre, and Prussian philosopher Immanuel Kant, were all the leaders of this movement was the adherent of the international organization so that whose insights were 
only mentioned in the history of the political beliefs debates and were not effective on the issue of international organizations which were later founded; although we should not ignore the Bentham and Kant's contributions in this regard because Britain representatives drew inspiration from Bentham ideas in the Second Hague conference (1907). Moreover, his idea led to the official publication of the League of Nations resolutions and the Convention on May21, 2012 on "Freedom of Communication of the League of Nations" in crisis period was the result of Bentham's ideas.

\section{Importance and Review of Literature}

Whatever is considered by elites as an accepted affair in international system is the interpretation of reality which is at least as important as the fact itself. In other words, the image of a country by others is at least as important as the reality. As constructivist stated, in this regard, countries apperceive each other based on their interpretations from each other andaccordingly adopt policy. Therefore, presenting a positive feature and image of the country and introducing it as a responsive country and adherent of the international regimes and the rules can lead to expansion of interactions and its adoption in the country as a responsible country in international arena and consequently lead to entrance of the foreign technologies and investments. In this regard, providing a positive image causes that its development is not considered as a threat for others (Fritz. 2006; 15). Thus, the positive look to the development of NGOs can be used in the realm of creating confidence to the young generation and using their capacity leads to win-win cooperation, in order to facilitate the process of changing country's feature in international system. Countries and traditional diplomatic institutions will reach to the role of YNGOs in providing a peaceful image of countries in international system, by wasting huge costs, or in the condemnation of various Human Rights violation acts including killing people in ethnic conflicts and extremism and/or other crimes against humanity or the spread of epidemic diseases especially AIDS or natural disasters. Meanwhile, most of the developed countries specially (France, Britain, USA and the Russian Federation) by using YNGOs do several international bilateral and multilateral programs by focusing and managing youth and in the realm of welfare and humanitarian acts in various fields including help in environmental protection and implementation of provisions related to these affairs in the UN Millennium Development Document in other countries.

The Resolution 2250 (2015) was proposed by Jordan and ratified by the UN Security Council and is called as historic Resolution on Youth, peace, security was focused completely on the role of young females and males in institutionalization of the peace and dealing with violent extremism, for the first time in the history of Security Council. Resolution 2250 is the representation of the unprecedented authentication about the urgent need of the participation of the young institutional makers in promoting peace and confronting extremism. This resolution also determines the position of youth and YNGOs as the main partners in universal attempts to confront violent extremism and promote durable peace. (The UN Information Center, 1394; 66).

The humanitarian and promoting peace acts by YNGOs in developed countries especially in undeveloped countries are needy and involve in violence and terrorism affect directly on the recruitment and change the active countries features in this regard. Meanwhile, it is worth noting that French YNGOs by holding several youth tours with the approach of helping to the AIDS patients in Africa and teaching them and/ or Russian YNGOs acts especially Gorbachev YNGOs after the War against Ukraine and entering to war-torn areas also their various supportive programs in Georgia, Kazakhstan, Turkmenistan, Uzbekistan, Tajikistan, Armenia and Crimea regions (fad.gov.ru.3214) are the obvious examples of these acts who move on the way of gaining national interests for aforementioned countries.

Thus, we consider that, in the present study, these welfare and humanitarian acts of YNGOs leads to forming new actor in diplomacy arena as the youth diplomacy by changing the view and creating positive image for the country. It is worth noting that since NGOs are as the main carriers of social capital, according to some scholars' opinions, potentially can emerge significant capacity to promote the level of social development and move on the way of gaining national interests (Jajarmi, 1388; 48) and moreover, contribute to their countries' public diplomacy.

However, the governments in undeveloped and least developed countries do not know the principle of "partnership" as an inherent and optional principle and believe that the responsibility and authority is completely the state (Sovereignty) property and consequently to the institutions; they act exclusive and closed and participate with a sensitive look and security; even they "interfere" and prevent the presence of people especially the young generation who are the potential forces for further development in decision-making and civil-decision making.

If we have a precise perception and clear recognition of literature, foundations and NOGs' activities, and look 
realistic at civil society concepts, social and cultural, capacities and social relations modernization in international era, globalization and the necessity of the expansion of international relations especially the presence, influence and effectiveness in societies and international official and professional organizations, and do not kick the social activists out from social scene and more important from the non-governmental institutionsby inadmissible labels and hallmarks or sulks and isolation; it does not lead to damages to the civil relations "youth-state" andusing their ability in gaining national interest with regard to the practical cases of the expansion of aforementioned NGOs.

Actually, the standard and ideal process for social relations needs the precise analysis of the current situation and its desirable origin. By utilizing the social responsibility "monitoring and consistency" youth can control the governments' monopoly, power and greed.

\section{International Documents in Youth Domain}

There are several international binding documents specified the youth rights and the necessity of the entrance and their cooperative activities as follows:

1) Universal Declaration of Human Rights

2) The United Nations Convention on the Rights of the Child

3) World Programme of Action for Youth to the Year 2000 and Beyond

4) Lisbon Declaration on Youth Policies and Programmes

5) International Bill of Youth Rights (Resolution No. XXXV 2633)

Youth development, also, is a term is proposed by some programmers especially the social and human resource development programmers (SeyyedEmamdi, 1388; 19). Similar to this term was used first for the women aimed at implying exhaustive concept so that can include other concepts such as growth, development, improvement, and flourish. It is also carrying out by youth participation in their affairs.

Since the UN General Assembly look at youth and women problems mainly from two aspects of Human Rights and Social Development (Resolution 1958/13), investigate the youth related issues in the form of its third committee, it means social, humanitarian and cultural affairs committee, and this survey consists of providing and or co-operation in providing the drafts of the plans and global action programs; resolutions, statements, recommendations and the related declarations to the youth domain.

As the General Assembly, the economic and social council proceed to resolve youth problems and consider social and economic problems youth confront with them by the ratification of related resolutions. Promoting NOGs partnership is another mechanism by the economic and social council in economic and social development to develop young people. At present, there are a considerable number of NGOs which are active in the social and economic fields and has e close cooperation with council by gaining the advisory position. In Article 71 of the UN Charter is accelerated:

"... economic and social council can provide proper arrangements in order to consulate with NGOs which deals with the matters under that council competency." In Resolution 126 (XLIV), 23 May 1968 such arrangements were appointed. Thus, conditions were prepared for none-governmental organizations to stay on the consultative status with economic and social council and have some counseling to that council's Secretariat.

According to this report, the holders of the consultative status are responsible based on the Resolution 1996/13 to adjust and provide a report on organizational activities in supporting the economic and social council and the UN every 4 years and if they failure, they will face with suspension of their consultative status for a period of one year in which they have to provide an acceptable reparative report otherwise their status will be withdrawn.

Since the non-governmental organizations are not considered as the especial consultative status in parts of UN, the usage of logo, letterhead, business card and banner of that organization is forbidden and the organization which holds the consultative status are allowed only to use the phrase "the consultative status of social and economic council of UN" under their respective organizations' name by citing the date of receiving that title.

It is worth noting that these holders can ask from the Security-General of the United Nations to put on the agenda of the related issues and interest to NGOs for the Council meetings, as well, propose their written or oral statement in economic and social council.

Aforementioned issues are indicating the importance and position of NGOs in international system and it shows the obvious future for countries which carrying out their cultural, social and economic affairs by the participation of NGOs. 
Now, NGOs act as public diplomacy system in international system with the difference that they can reflect a view of the society's fact into the international system without the interferences of the governments, in other words, in developed societies by devolving some basic affairs of society as well as increasing the public partnership in their inherent affairs use the hidden capacity of the country in developing and remediation and cultural promotion and finally the countries national security.

But regarding the related research with the activities of NGOs can be mentioned the followings:

In aresearch titled "Analyzing the results of NGO Peace Practices": by Dumas, in 2010, it examined the methods of using NGOs capacity, by the humanitarian approach in the form of a case in crime and Human Rights Violation in Congo.

Joe Anderson in a research:" On Nationalism, Ethnicity and Non-Western Societies" in 2010 examined the diversity of ethnicity and nationalism in non-west and nor developed societies. He believes that non-governmental organizations in Asia and Oceania play the main roles in political consultations and always their knowledge and experiences influence the governments' preferences and developing programs in national level and lower than that. These organizations have the main place in information and data processing and attracting the attention of decision makers to the existing facts. NGOs use communication, informational, training and consulting approaches to promote the concepts of this domain among public thoughts in the field of family planning programs. The family planning institution in Sri Lanka was founded as a NGO in 1953 before the government recognizes the family planning programs in 1965. During these 10 years, this institute could provide effective consulting in order to legitimate the family planning program and some tools for social changes.

Other research entitled "The foundations of practical training for young leaders" carried out by Edward Simpson in 2012, in which referred to the youth empowerment programs affective on the domestic affairs of countries by NGOs. In this study it is expressed that forming the identified training infrastructure for youth by economic and social council of UN by NGOs can play a role in their networking.

It is clear that no especial study was done yet on the role of YNGOs and their role in foreign relations, but here we are referring to this issue.

Youth diplomacy as a new actor in the field of modern diplomacy:

Diplomacy between countries was referred, in the past, to the issues such as personal and family ties between the two countries' kings with each other or it was related to the war and peace issues, but in the current situation other issues are considered moreover such as commercial relations, cultural and scientific ties at the core of diplomatic debates among various countries with each other and among them and international organizations.

Indeed, diplomacy is the executor of the foreign policy in the foreign policy doctrine framework of each country.

A country's foreign policy doctrine which is usually considered as the general expression of its foreign policy is announced by the leader of the state or its minister foreign affairs.

Providing general principles to lead foreign policy and carrying out the diplomacy are the objectives of the foreign policy doctrine of each country. These principles allow the political leadership deals properly with the various happened situations and explain the country's behavior against other countries.

Executing the policy is the responsibility of a group which is called "diplomatic board". This group is considered as the official representative of the sender country to the recipient and host country. Its task is protecting the interests of the sender country's government and citizens to the recipient country. However, it will be carried out in the permitted boundaries framework by international rights, negotiating with the officials based on determined principles by the sender country and other legal means which were recognized by the recipient country.

But by expansion of technology and communication technology, the atmosphere changed from the official diplomacy to the public one and the glossary of the international relations of the US Department of State, public diplomacy is defined as follows:

"Programs which come into force under the state advocating with the aim of informing and influencing public thoughts in other countries."

"Public diplomacy is what we benefit though cooperation with populace outside the country to achieve to their strategic international preferences." (Leonard, 2002; p.8)

Since the public diplomacy is considered a pictorial oriented activity which is based on the asymmetric unilateral relations model and governments try to create a positive image of their countries outside their realms, by the 
growth of technology and the expansion of communication atmosphere, this model changed to a bilateral model and adverting was focused of dialogue and mutual interactions rather than managing image.

In this model audiences' feedbacks from received messages were analyzed. Persuasion through dialogue is the intensive program of the modern diplomacy.

The plurality of cultures recognition causes looking at the universal culture take place by diversity approach rather than cultural assimilation, in other words, each society has its own culture and should be percept based on its standards. By the expansion of NGOs role in developed countries and according to the youth role and the nature of reform and full of energy, they used their capacity to help public diplomacy in their own country; therefore, the youth diplomacy term was spread among elites.

Youth diplomacy consists of some actions in which youth are interested in the national interest along cooperating with other youth abroad the boundaries in order to achieve the long term international strategy.

By using creative and fervent young people, Youth diplomacy is seeking promoting national interest through the masses of the young people in the world, recognition, informing, influencing foreign audiences, sending messages to other audiences, the spread of dialogue among youth, carrying out international models and exercising the universal management, the world's elites' friendship with each other, and believing the national humanitarian strategies. (Wolf and Rosen, 2004; p.5)

As mentioned in previous discussions, nowadays, social capital play more important role than physical and human capital in societies especially in the area of governing affairs, amplification of political legitimacy and increasing the soft power. Other capital will lose their efficiency in the absence of social capital and without social capital, paving the developing ways and cultural and economic evolution is rough and tough.

According to the Secretary-General of the United Nation, the international programs of the youth diplomacy were in some of the most sensitive issues such as drug prevention, promoting and boosting Human Rights and supporting AIDS patients. As well, YNGOs have significant contributions in creating proper patterns for social protections and attentions. (UN Information Center, 2013:16)

Since these organizations are raised from the community and passed the forming natural process and some interested ones to an especial topic gathered each other and as well due to their powerful organizing, the existence of these organizations causes the flow of collective processes, mechanism of sustainable development such as culture, art, politics, women, environment and etc. in their specific channel by complete transparency.

Nowadays, paying attention to promoting Human Rights is not limited to active non-governmental organizations in the realm of philanthropy. It is so wide that even commercial unions, trade organizations, professional societies, political reformer groups, ethnic, local and religious group and other groups in community have been considered Human Rights and its promotion in turn from their own special point of views and based on the intended group interests.

Non-governmental organizations (NGOs) provide various groups to enter them in social activities arena by supporting them also provide the setting for social adoption. Governments support derelict women and or orphans or homeless children, are example of these organizations. These organizations help the above groups by providing material and moral aids to take useful and constructive role in society. Another obvious example is, in this regard, the organizations support migrant workers and refugees.

Non-governmental organizations gave a lot of efforts to create the status of "high commissioner on Human Rights", convincing the principle of universality of Human rights in the global level and creating the international tribunals in Yugoslavia and Rwanda. 
Table 1. Separation of diplomacy function with soft and hard power approach

\begin{tabular}{|c|c|c|c|}
\hline & Behavior & Sources & Government policy \\
\hline \multirow{3}{*}{ Military Power } & Compulsion & & Compulsory diplomacy \\
\hline & Prevention & Threat of Force & War \\
\hline & Ruling & & unity \\
\hline \multirow{2}{*}{ Economic power } & Persuasion & Reward & aid \\
\hline & Compulsion & Boycott & bribery \\
\hline \multirow{4}{*}{ Soft power } & \multirow{4}{*}{ Planning absorption } & Values & Boycott \\
\hline & & Culture & Modern policy, Youth policy \\
\hline & & Policies & Bilateral and multilateral dinlomacy \\
\hline & & Institutions & 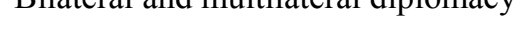 \\
\hline
\end{tabular}

Meanwhile, youth diplomacy affects the international politics program through nongovernmental diplomatic actors. They entered various arenas to enable their goals. It is worth nothing that we refer to the success of NGOs in the field of their objectives realization based on proper and effective usage of new informative technology.

\section{Function of Soft Power by Using the YNGOs Capacity in the State's Foreign Relations}

Recently, the soft power component finds a proper position in world political literature and power approaches and every day new dimensions of it will be appear. Power is one of the basic and fundamental elements in international policy. So the arena of analyzing power is one of the most important areas of research in international relations which will discuss, based on various methodologies, to explain the governments' foreign behaviors. Checking the evolution in political structure and behavioral pattern of countries, based on that, shows every changes and displacements resulting from the changes in power-oriented approaches. In the concept of power, evolution which is recalled "soft power" is considered as a relatively new and young pattern to discuss in the field of international policy and a mean to improve the foreign policy of countries that somehow is based on the its synonyms such as influence, authority and even legitimacy. This power is the power of leading, attracting and being model. For this reason, it has close relationship with unshaped powers such as culture and technology. Accordingly, developed countries which have the means of operating this capacity are going to expand and distribute culture and their knowledge as components of soft power in order to achieve to their three goals: promoting the amount of political system legitimacy in international arena, reserving the international prestige and finally managing and directing public thoughts to consolidate their hegemonic structure. Using the private capacities especially NGOs to explain and spread this to help public diplomacy leads to put easily the public thoughts under influence of countries advertising programs.

One of the differences mode of today' world from the ancient one is the position of countries soft power and their ability in creating gradual and subtle but profound changes in the beliefs system, lifestyle, political positions, attitudes and the social preferences of audiences by applying this soft power.

This differentiation is in the way that can be considered seduction, attraction and absorption are always more used than force, and coercion and gaining reputation, international credit and influencing in the public thoughts, and parallel achieving the soft power, and even beyond earning this consequence in the national level are among the important goals of countries and it can be followed in accordance with status, position, facilities and opportunities of each country in international arena based on various methods and from several channels and ducts.

Reflecting a positive image of a country is not a new matter, but conditions for soft power has changed significantly in recent years. Indeed, information is somehow a power and how to use it by a country determines the amount of that country's effectiveness on influencing universal politics and with no doubt the ability to distribute the information and being unbelievable are considered the main sources of its attractiveness. 


\section{Soft power Hard power}

\begin{tabular}{|c|c|c|}
\hline $\begin{array}{l}\text { Behaviors } \\
\text { spectrum }\end{array}$ & Ruling compulsion reward & Planning attraction persuasion \\
\hline $\begin{array}{l}\text { The most likely } \\
\text { resources }\end{array}$ & $\begin{array}{l}\text { Compulsion } \\
\text { Boycott }\end{array}$ & $\begin{array}{l}\text { Institutions } \\
\text { Values } \\
\text { Culture } \\
\text { Policies }\end{array}$ \\
\hline
\end{tabular}

Public diplomacy has three different dimensions. Firs dimension includes daily communication which explains the framework and the background of decision making in at home and foreign policy. Democratic governments are usually aware of proposing articles in domestic press after decision making, while foreign press should be taken into account as the most important aim of the first dimension of public diplomacy.

In other words, they should emphasis on their perception of the effect of their actions and explanation of the effect of these actions in the country's international image. The second dimension of public diplomacy is about the strategic communications in which a set of common threads are extended which resemble the political and advertising campaigns. In these campaigns, symbolic communications and events are planning in order to identify basic issues or promote the government policy.

The third dimension of public policy is the developing of stable relations by key characters over many years through scholarship, cultural and academic exchanges, training, holding seminars and conferences, cheerful programs and various shows along youth participation in United States or other allied countries, holding training course and the activity of youth tourism and creating a network for accessing to communication channels among young people. Some parts of this matter happen by using the capacity of YNGOs to not specify the main role of states and as well these organizations can move in the way of empowering themselves and helping the national interests. The importance of the US cultural and academic exchanges is due to the training of most of the main leaders of the world. In the public policy dimension it plays an important role in creating an attractive image from a country. In other words, creating a positive image from a country in public thoughts is one of the most important achievements of these programs in order to gain national interests. This can trace promising perspectives in the field of reaching to favorable outcomes. Success is depending on the policy adopted in this field. Politics and diplomacy should be in accommodation and compatibility with each other, otherwise public diplomacy marketing will be changed to barrage of mixed and disordered messages. Moreover, it should be noted that public diplomacy should be a two-way street which comprises listening as well as speaking. Soft power is based on some common values and it is said that, based on that reason, interchanges are often more effective than unilateral broadcasting. Therefore, the efficiency of soft power requires understanding that how others hear our messages and accordingly we set our messages. Understanding the target audience is the main issue in this field. Because all information passes cultural filters and hence the audience will rarely listen to the grandiose speech which is intended. Speech is less effective than actions and symbols. Thus, we can identify three kinds of power in the information universal era based on the following table.

The National Council of Youth Actions was founded in the United States that its main site is in New York with the aim:( identification and protection of the youth positive actions, to ensure transferring youth messages to the highest authorities of the country, promoting the mutual understanding, representing the youth interests, emphasis on the equality of men and women rights, developing youth international relationship, youth development efforts, development of the YNGOs activities and communication a rapprochement with young leaders) and with programs such as holding meetings and annual conferences.

This council identifies effective and active young people in various social, cultural arenas and discuss regarding common literature especially in the field of humanitarian by YNGOs cooperation and US universities and charities financial supporting through holding annual courses of young leaders. Actions of this set and holding aforementioned conferences causes that participated youth in these conferences identify and absorb talented and active youth of other countries and promote the principles of humanitarian through the American approach. 
(www.youth.nsu.ru/432/jhk)

- Italy youth international relations committee:

Italy youth international relations committee ' goals include:

1. Promoting cooperation among national Youth Organizations;

2. Promoting the aid of YNGOs to the national, local, and international societies based on peace and cooperation, unity and the autonomy of nations ethnic groups;

3. Attempt in order to achieve the goals and principles of the UN Charter, goals and principles of Organization for Security and Cooperation in Europe and Council of Europe.

Activities and programs

The main activities of the European Youth International Relations Committee are as follows:

1. Collecting and distributing data in the field of Italian youth problems;

2. Doing necessary actions and coordination to facilitate and boost the relation between national and international level;

3. Holding seminars, conferences and meetings on political and international issues;

4. Doing measurements in order to make close the member organizations and relation with YNGOs in other countries.

- $\quad$ The Federal Assembly of the Youth German NGO

\section{Goals}

1. Creating mutual understanding in order to promote and encourage the interchange of experiences and facilitate the cooperation fields;

2. Participation in solving the youth employment problem;

3. Promoting youth characteristics through advancements of democratic and social behaviors, political training, perfect training and the improvement of the youth German cultural interest with other countries;

4. The struggle for women and men rights equality as well as fight against sexual abuse of youth;

5. Efforts and cooperation in codification of youth policies;

6. Encourage and implementation of measures and common meetings and if necessary, creating common mechanisms;

7. Cooperation with institutions and organizations in training field;

8. Fight against racism and totalitarian orientation.

- Canada universal YNGOs:

The universal goals of youth include:

1. Increase the individual ability especially the youth to active participation in fair development and creating stable and democratic societies;

2. Creating proper fields for learning, skills and necessary values for active interference of youth in society;

3. Providing required fields for participation and cooperation with other countries' youth, organizations, societies, individuals and group to take effective action in resolving youth problems;

4. Expanding the role of youth in development and progress of their societies and advertising and promoting the universal peace.

- $\quad$ Creating a network of people with various cultural backgrounds and uniting them through mutual respect and understanding, so that these differences cannot prevent them for achieving to the peace and calmness;

- Holding conference of north-south youth

- $\quad$ Providing emergency services in the form of financial aids and direct planning for Colombian homeless in earthquake in 1985;

- $\quad$ Executing the collaborative program which provide an opportunity for youth to work in other parts of the world in written and codified projects by local groups (1988); 
- $\quad$ holding training courses in Sri Lanka and Koady institution in which participants trains about how to create small commercial and cooperative companies (1989);

- $\quad$ executing changing cycle projects in which 12 youth travel by bicycle to Ontario and Colombia-British to participate in international development workshop, environment protection and justice (1993);

- Executing programs in central and eastern Europe;

- $\quad$ Executing the project of Canada and the world youth perception ; in this program young people learn more about the world around themselves and Canada and gain leadership skills and participate in voluntaryactivities in the host countries;

- Cooperation with high schools, colleges, universities representatives to organize their programs in developing countries.

\section{Achievements}

\subsection{YNGOs Functions in Youth Diplomacy}

\section{A) Communicative Network}

One of the Youth diplomacy and YNGOs applications is establishing a long term relationship with other effective and active youth in the world and/or YNGOs to create common perception of welfare and humanitarians programs of their country to others.

In other words, they amend the misinterpretations and seek arenas in which can achieve to common concerns by relationship means perception of other countries' needs, cultures and transferring their point of views.

Building relationship needs long-term interchanges with active and affective youth in other nations. Holding conferences, seminars, creating virtual and real networks and at a high level face-to-face relationship through nongovernmental and friendly relations of different youth countries.

By non-governmental organization, youth are not looking to establish mere relationship with other youth in the world, but they are looking to establish purposeful relationship and leveraging.

Familiarity with other countries perception, culture and values, their public interactions, beliefs and convictions can be important in recruiting from the opposite side and gaining national interests.

\section{B ) Managing the country's mode}

1. Familiarity with the country's mode and feature among others around the world;

2. Using the NGOs capacity and other civil institutions to improve the country's feature among public thoughts by doing welfare and humanitarian actions.

Today we can promote the international mode of a country in the world by doing an intelligent action. In contrast, each unconsidered action has its own damaging consequences.

Representing and promoting the positive image with strategy "high to high" in developing the country reputation in the international community and helping in national interests is crucial. Absorbing the different countries youth thoughts and harts is crucial in managing the country's feature. (Kelley, 2009; p.79)

According to Jean Baudrillard, the post-modernist philosopher, managing image will happen through managing the understanding of the target audience with the induction of messages in the mind of audience by various means including, poetry, music, movie, seminar, contest, entertainment, etc. however, since the youth procedure is along reform, excitement, exhilaration, curiosity and change, by using the trained and loyal young force to the country's national interests can achieve to the goal of managing target audience perception more accurately.

\section{C) Accreditation}

Since YNGOs have audience-oriented approach and work on the audience perception, therefore, it causes accreditation. Being gelatinous and in other word being flexible has the effective role in increasing reliability and credit.

D) Updating the image of universal audience

YNGOs change the mental image of audience as a representative of target country by doing actions which are the public attention and concern in the world and trigger their undesirable beliefs toward positive interpretation and admiring the country.

\section{E )Influence}


Influence causes audience supports target country's programs and supports it in various programs and advertisements and even put pressure on statesmen by recruitment and changing the audience view to the target country.

\section{F )Creating a new method of communication}

Communication is like a linear process of transferring information with the aim of persuasion or controlling the public thoughts in public diplomacy. The main concern was that what is our message and transform it through media to others.

But, with nongovernmental organizations, the youth who are active in humanitarian arena in international system are following the recognition of similarities or popular mutual interests and reach to dialogue from monologue in other words, persuasion through dialogue and receiving feedback at the same time and reaching to common points.

- $\quad$ Boosting skills with target audience

- Tolerance in listening to the people's ideas (listening carefully) and the ability to listen to the vain and repetitive words

- Ability to identify the common pointsdiscourse and negotiate on it

- Ability to make friends and coming close to the opposite side

- familiarity with the structure and the agent in international system

- Proficiency in NGOs coordination

- familiarity with up-to-date social networks and membership in them and ability to launch a special channel

- dominance on information pattern " high to high"

- recognition of cultural pluralism pattern

As it was referred, various functions of public works (welfare) and philanthropic of YNGOs I international system according to the recruitment and even networking among NGOs and sending real messages of altruism to the societies which faced with damages and human suffering will help naturally in the way of public diplomatic programs of countries and gaining national interests also helping in positive improvement of country's mode in international system.

What is definite is, creating a democratic society has a close relationship with the emergence and expansion of third part which is located between the state economy and free market and such a close relationship with the special function of organizations means it has voluntary or non-governmental organizations. NGOs have the main role in democratic process which is mentioned in Article 19 and 20 of the Universal Declaration of Human Rights under the title of the rights to freedom of assembly, and freedom of expression and freedom of association are stipulated in it.

Finally, over the two decades the programs and solutions of the UN were on the issues of women and youth, helping to protect sustainable environment, protection against colonial acts, training and such cases, but after 1980 the issue of development based on social participation and empowering young human resources were seriously on the agenda of the UN.

\section{References}

Abrahamiyan, P. (2012). People in Iranian Politics, Five Case Studies. Cheshmeh pub., Tehran.

Afrogh, E. (2003). Non-governmental organizations and Law provisions. Quarterly Journal of the Supreme Cultural Revolution Council, (189), 50-66.

Afzali, R. (2011). The Perspective of civil society in Middle East, with the introduction of Sarioalghalam, Mahmood. Bashir science and literature pub.; Tehran.

Ahmadi, H. (1998). Realization of Civil Society in Islamic Revolution's Article series. The Cultural Documents of Islamic Revolution organization; Tehran.

Ahmadi, H. (1999). Article series of Civil Society and Iran's Today. Naghshonegar pub. Tehran.

AlaviTabar, A. R. (1999). Article series of civil society and Iran's today. Naghshonegar pub. Tehran.

Amartyasin, A. (2013). Development as Freedom. Movaseghi, Ahmad. Ney Pub; Tehran.

Ameli, S. R. (2011). The interaction of globalization and citizenship and religion. Quarterly journal of Social 
Science, (18), 20-33.

Amin, F. (1995). An investigation on non-governmental role in people's participation to environmental protection. MA thesis, Faculty of Law, Tehran University.

Anvari, E. (2009). Non-governmental Organizations and Human Rights in Iran.Political science quarterly book. $5^{\text {th }}$ year.No. $31.18-36 \mathrm{pp}$.

Ashouri, M. (2004). Alternatives to Prison Sentences. Tehran University publication; Tehran.

Ashraf, A. (1999). Guild System, Civil Society and Democracy in Iran. Goftego Quarterly Journal, (27), 42-54.

Azimi, H. (2013). Collection of Iran- religion - Ideology- democracy and its obstacles.Iran Farda monthly Book. No. 40; 39-40 pp.

Barston, R. P. (1988). Modern Diplomacy. London Longman.

Bashiriyeh, H. (1998). Civil society, Ideology's power: Obstacles of realization of civil society in Iran, from the book of realization of civil society in Islamic Revolution of Iran (Article series). Cultural Documents of Islamic Revolution organization; Tehran.

Bashiriyeh, H. (2002). Obstacles to political development in Iran. Gam Noor pub. Tehran.

Bashiriyeh, H. (2004). Reason in politics: thirty-five-speech in philosophy, sociology and policy development. NegahMoaser pub. Tehran.

Berridge, C. R. (2002). Diplomacy Theory and Practice. UK Palgrave.

Breitmeier, H., \& Rittberger, V. (2000). Environmental NGOs in an Emerging Global Civil Society. Boston,Ma: Institute for Development Research.

Bzarganan, M. (1998). Iranian adaptation. Bita pub. Tehran.

Charnovitz, S. (1996). Participation of Non - Governmental Organization. University of pennsylvania Journal of International Economic Law.

Djerejian, E. (2007). War and Peace: The problems and Prospectes of American Diplomacy in the eEast. Los Angeles word Affairs cuncil.

Fakohi, N. (2004). Key concepts of citizen and urban culture. Ney pub. Tehran

Ghavam, A. A. (2006). Theories and approaches' international relations. Samt pub. Tehran.

Haji Yousefi, A. M. (2012). Government or civil society's relative autonomy. Quarterly Journal of Strategic studies, 70-79.

Hesam, F. (2004). Media and social values' interpretation. Journal of previous general culture, (80), 60-71.

Jabarri, H. (1392). Social and economic development. Welfare journal, (10).

Karns, M. P., \& Mingst, K. A. (2011). International Organizations: The Politics and Processes of Global Governance. London: Lynne Rienner Publishers.

Keddie, N. (2003). Modern Iran Roots and Results of RevoLution. New Haven, Yale University Press.

Keohane, R. (2005). After Hegemony: Cooperation and Discord in the World Political Economy. New Jersey. Princeton: Prinction University Press.

Kolaee, E. (2005). Perspective of democracy in Iran. The Newsletters of the female's studies association; No. 10; 19-29 pp.

Lamton, N. K. S. (2001). The government theory in Iran. Pahlavan, Changiz. Giv pub. Tehran.

Lypest, S. M. (2003). Encyclopedia of the translators' team democracy. Foreign Ministry pub. Tehran.

Mohammad Mahdi, K. (2008). Facts on citizen policy. Social and Cultural Studies Department of Planning. Pub. Tehran.

Mosazadeh, R. (2009). International organizations. Mizan Legal Foundation; Tehran.

Naghizadeh, M. (2003). The theory of citizenship and culture and Iranian civilization. The magazine of political-economic information, (183), Tehran

Namazi, M. B. (2001). Overview of the non-governmental organizations. Jihad; Tehran. Jameh Pub. Tehran

Namazi, M. B. (2001). The review of the current situation of the non-governmental organizations in Iran. The 
Ministry of interior's research and policy studies department of the partnerships and Basij office.

Ramezani, J. (2005). Predicate on civil society. Two weekly journals of Tolo Ghanitay. No. 5. December

Ramezanzadeh, A. (2013). Course pamphlet on Minorities' rights.Faculty of Law and Political Science; Tehran University. No. 55; 9-16 pp.

Razavi, M. R. (2001). Competitive ability and contracting relations. Social science quarterly journal, 19, 8-18.

Rittberger, V., \& Zangl, B. (2010). International Organizations: Polity, Politics and Policies. Palgrave Macmillan in the UK/St. Martin's Press LLC in the US.

Sabzevari, N. (2002). Local organizations or democratic infrastructure. PhD. Thesis; Tehran University.

Soleymani, M. (2003). Study of the non-governmental organizations' role in pursuing social demands. Hamshahri Newspaper, 14.12. p.9.

Tajbakhsh, K. (2004). Preliminary study of the social capital theory in analyzing the social security situation in Iran. Social security research institute.

Tvasoli, Gh. A. (2005). Government and non-governmental organizations. Especial issues 2011, Shargh Newspaper, p.51.

UN information Center. (2002). Report of Secretary-General to the General Assembly Special Summit on AIDS.UN organization publication office. Tehran.

United Nations Conference on Sustainable Development(UNCSD), so called Rio Bob Reinalda, "Routledge History of International Organizations(2009);: From 1815 to the Present Day". London: Routledge.

United Nations Development Program website: http://www.undp.org

United Nations High Commissioner for Refugees website: http://www.unhcr.org/cgi-bin/texis/vtx/home

Waltz, K. N. (2011). Theory of International Politics. Addison-Wesley, Reading, MA, and Gilpin.

Weiss, T. G., \& Daws, S. (2009). The Oxford Handbook on the United Nations. Oxford: Oxford University Press.

Zakeryan, M. (2003). Human Rights in new millennium. UN Action Programme; Tehran.

Zakeryan, M. (2004). Human Rights and Middle East. The center of Middle East scientific and strategic research; Tehran.

Zokaye, M. S. (2002). The situation of social capital in Iran. Davtalab Magazine, (8), 81-90.

\section{Copyrights}

Copyright for this article is retained by the author(s), with first publication rights granted to the journal.

This is an open-access article distributed under the terms and conditions of the Creative Commons Attribution license (http://creativecommons.org/licenses/by/3.0/). 